\title{
Local Governance of Devolved Hospital Services: The Bukidnon Model
}

\author{
ANTONIO T. SUMBALAN \\ atsumbalan@gmail.com \\ Liceo de Cagayan University
}

Date Submitted: July 27, 2007

Final Revision Accepted: September 29, 2007

\begin{abstract}
The study is anchored on the concept of decentralization, which is to overcome the failure of central government in addressing people's needs and priorities. Specifically it deals with devolution, which is one administrative category of decentralization that typically involves legal transfer of administrative powers to political units. This is essentially a public administration conceptualization of decentralization to improve the efficiency and effectiveness of service provision through reallocation of decision-making and resources to peripheral areas. The conclusions of the study are the following: (1) the provision of hospital services can be a potential income center and not entirely an expense account; (2) devolved hospital services can sustain the hospital's operation and ensure that services are accessible to the poor; (3) the translation of health development plan to improve health service delivery necessitates local government's strong political will; (4) to operate the devolved hospitals as income centers is a major shift in governance with the view of sustaining hospital operations; (5) the Bukidnon model provides for a win-win situation for both the PhilHealth and the Provincial Government; and (6) the Bukidnon hospital system demonstrates cost-efficiency through an appropriate mix of primary, secondary, and tertiary hospitals.
\end{abstract}

Key words - Local governance, devolved hospital services. cost effeciency 


\section{INTRODUCTION}

Health system reform has been a priority issue for governments and communities in the Asia-Pacific region. Most policies focus on reforms in the area of health services decentralization. Decentralization involves delegation of powers from central towards provincial or district departments of health. It can be defined in general terms as the transfer of power in planning, management, and decision-making from the national level to sub-national levels of government (Bossert \& Beauvais 2002).

Devolution is one administrative category of decentralization that typically involves legal transfer of administrative powers to political units. In this situation, health providers then come under the management of non-health managers. This is essentially a public administration conceptualization of decentralization. The intent of decentralization and devolution is to improve the efficiency and effectiveness of healthservice provision through reallocation of decision-making and resources to peripheral areas (UNDP 1977).

Hospital services are the devolved functions to the provincial government under the 1991 Local Government Code. These services refer to medical and surgical services and the supporting laboratories, equipment, and personnel that make up the medical and surgical mission of a hospital or hospital system (R.A. 7160 1991). This study assessed the performance of the Provincial Government of Bukidnon (PGB) in its ability to operate and manage the devolved functions of providing hospital services from the Department of Health pursuant to Republic Act 7160, otherwise known as the Local Government Code of 1991. It identifies the innovative features of local governance initiatives to make devolution more successful and sustainable. The framework used in the assessment is the Fourmula One for Health.

The PGB is a first class province that operated on a Php 1,443,852,195 budget in 2007. In 1992, the Department of Health devolved 5 hospitals to PGB. These consist of a tertiary hospital (Malaybalay) with an authorized bed capacity of 100 beds; a district hospital (Maramag) with a 25 authorized 25-bed capacity; a two 10- bed authorized primary hospitals (Talakag and Kalilangan); and another two 10-bed authorized primary hospitals that are still to be completed (Kibawe and San Fernando). The Kibawe Primary Hospital was opened in 1993 while the San Fernando Primary Hospital became functional only in 1996. The province also established a 10-bed authorized primary hospital in Malitbog that was opened in 2002 but was only accredited by PhilHealth in 2004. A new authorized 24-bed capacity secondary hospital in Manolo Fortich was opened late 2007.

The documentation of the Bukidnon experience hopefully will inspire other local government units in their quest for innovations to effectively deliver government services in a devolved setting. 


\section{OBJECTIVES OF THE STUDY}

The study pursued the following objectives: (1) to determine the financial resources of the Provincial Government of Bukidnon in terms of revenue generation and allocation with focus on its financing of the delivery of tertiary health services through the hospital system ; (2) to describe the initiatives of the Provincial Government of Bukidnon with regard to its devolved hospital services in terms of: a) service coverage and accessibility, b) facility development, and c) human resource development ; (3) to determine the specific actions of the Provincial Government in sustaining the cost of operations of the hospitals in terms of revenue generation and fund management; and (4) to draw out the potential best practices that may sustain the effective delivery of tertiary health services from these devolved hospitals.

Hopefully, this study will contribute to the current discussion on the wisdom of devolving the delivery of tertiary health services to the provinces and the coping mechanisms to address the issues and concerns in the operation of the hospitals.

\section{METHODOLOGY}

The study used the descriptive method of research, applying documentary analysis technique that reviewed relevant documents pertaining devolution of hospital services and the annual reports of the Provincial Government of Bukidnon from 2002 to 2007 as basis for an informed assessment of hospital services performance. An interview with the Provincial Governor, the senior officers and staff of the Provincial Government of Bukidnon and a Focused Group Discussion (FGD) were also conducted.

An interview schedule and discussion topics guided the discussion during the interview and the FGD respectively. The results of these activities validated the secondary data obtained in the documentary analysis. Further, the results were used in the conduct of Consultative Planning Workshop among the key actors of the Bukidnon Hospital System. The framework for Fourmula One as developed by Herrin (2008) served as guide for the conduct of the study. This is presented as follows:

REFORMS:

1. Financing

2. Regulation

3. Service Delivery

4. Governance

\section{FOURMULA ONE} GOALS:

Better Health Outcomes

Equitable Health Care Delivery

More responsive health system
OUTPUT

Improved

Quality of Life

\section{RESULTS AND DISCUSSION}

\section{Financial Resources of the Provincial Government}

The actual revenue of Php 1,268,907,564 for 2007 of the Provincial Government 
Liceo Journal of Higher Education Research

shows that the bulk of the income generated comes from its share from the Internal Revenue Allotment (IRA) that accounted for 76.22 percent. Hospital income ranks second as major revenue contributors, chalking in 10.42 percent or Php 114,150,489.00. It is noteworthy to find that fund transfer from the Philippine Health Insurance Corporation to the Province, the PhilHealth Capitation Fund accounted for 4.42 percent of the total revenue realized for 2007 or Php 48,379,500.00. Thus, it can be argued that the devolved tertiary health care of the province can financially stand independent of the Local Government Units.

The revenues generated from hospital operations and related health service from 2002 to 2007 suggests that the bulk of hospital income comes from the PhilHealth remittances. There are two types of these remittances to the province. The first one refers to PhilHealth Capitation Fund (PCF) that is transferred to the province with its enrolled families under the PhilHealth Sponsored Program. The PCF is a financing mechanism where an accredited publicly owned facility, the Provincial Health Station in the case of Bukidnon, is reimbursed a fixed amount of Php 300.00 for every enrolled sponsored indigent.

The second is the PhilHealth payments of provincial hospital claims for reimbursements. The reimbursements are the results of the services provided by the provincial hospitals to individuals seeking medical services who are covered by the PhilHealth insurance program. The PhilHealth reimbursements from 2002 to 2007 averaged 61.11 percent of the hospital revenue generated for the period reported. This proves that PhilHealth payment is the main source of hospital income.

However, it noted that based on the projected annual income for the hospital for 2007, the realized amount of Php 114,150,489 represented only a collection efficiency of 74.12 percent. The unrealized income was accounted for a receivable of Php 8,703,888 or 5.65 percent from the PhilHealth Corporation as reimbursement. This was the offshoot of the "No Excess Payment" policies for indigent patients. This cost the province some Php 30,813,051 or 20 percent. Thus, the province has an unrealized income of only Php 332,572 or 22 percent based on its 2007 projected income.

Moreover, the sources of the hospital-generated revenue of Php 114,150,489 for 2007 showed that the bulk of revenue was from PhilHealth reimbursement of the sponsored indigent families reaching Php 68,814,250. The paying patients contributed only Php 30,956,697. Payment from GSIS and SSS covered patients of the hospital shared the balance of Php 14,379,542. The actual collected revenue of Php 114,150,489 further showed that 68.19 percent came from medical, dental; and laboratory fees while 31.59 percent was came from hospital fees.

The participation of the province in the sponsored indigent program of PhilHealth had contributed to the income generated by the Bukidnon hospital system. The PCF from 2002 to 2007 reached Php 301,209,500 generated over the same period resulted to total revenue of Php 754,189,559 for the Bukidnon hospital system. Table 4 shows the number of families enrolled, the income generated under the PhilHealth Capitation Fund, and the reimbursement of services provided by the provincial hospitals from 
2002 to 2007.

\section{Financing Delivery of Devolved Tertiary Services}

Financing the delivery of devolved tertiary services in the province from 2002 to 2007 is basically sourced from locally generated revenues. The province has to avail of a loan from the Land Bank of Philippines for the construction of three hospital building facilities costing Php 213,321,880 in 2004 (Provincial Accountant's Office, 2008).

The consolidated hospital operating cost for the operation of the devolved provincial hospitals (2002 to 2007) reached to Php 857,121,344 or an average annual operating cost of Php 142,853,557. The bulk of the expenditures were accounted for Personal Services and Maintenance and Other Operating Expenses (80\%). This was followed by expenditures for Drugs and Medicines (12.15\%), and for medical supplies (7.85\%). Likewise, the total operating cost the Provincial Health Stations was Php 200,141,719 for 2003 to 2007. Assessment for bulk of the expenditure was the maintenance and other operating expenses (MOOE), followed by medical and dental supplies $(38.86 \%)$. Personal services accounted for only 8.69 percent.

The other cost incurred by the province was the premium payment made to PhilHealth. The payment ensures that the indigent families of Bukidnon can have access to the devolved tertiary health services. The total amount spent for premium payment to the PhilHealth Corporation from 2002 to 2007 was Php 406,596,695. However, technically the province only spent Php 105,387,116 due to the reimbursement scheme under the PCF. This amounted to Php 301,209,579.

\section{Local Initiatives for Devolved Hospitals}

On health services, the Provincial Government focuses on ensuring an expanded coverage of public health through the provincial hospital system. It also strives to enhance access, especially by the poor, to personal health services as well as to reduce the financial burden of individual families. These are pursued through the all-out participation of the province in a universal coverage of the National Health Insurance Program (NHIP) in Bukidnon. On hospital reforms, the objectives are to provide fiscal and managerial autonomy to provincial hospitals to improve the way hospitals are governed and financed. The reforms are geared towards quality hospital services, cost efficiency, enhanced revenues, and reduction of dependence on direct budget subsidies.

\section{Service Coverage and Accessibility}

To improve service tertiary healthcare services, the Provincial Government went into three major activities; the full participation in PhilHealth Medicare Para sa Masa Program, establishment of the Provincial Health Stations for outpatient and diagnostic services, and the formulation of hospital buildings development program. The Medicare Para sa Masa (MPM) is the PhilHealths main instrument to addresses the 
health problems of the poor. The Indigent Program of the National Health Insurance Program (NHIP) offers the standard benefit package to the poor without individual contribution. The package includes primary consultation with general physicians, free laboratory services such as chest $\mathrm{x}$-ray, complete blood count, fecalysis, urinalysis, and sputum microscopy.

Under the program, the province enrolled a number of indigent from 155,826 families in 2002 to 161,265 in 2007. This earned the Provincial Government of Bukidnon the distinction of having enrolled the highest number of families under the sponsored program and thus fully complied with the universal coverage of its population under the National Health Insurance Program. The enrollment of 161,256 families in 2007, for example, can be translated into the province's covering 80 percent of the population of 1,209,448 (NS0, 2007 Census of Population). This is based on the assumption that an average family size is 6 individuals.

\section{Health Facility Development}

The province's efforts on health facility development consisted of the establishment of the Provincial Health Stations and the development of hospital buildings. The health facility development has twin objective. It is aimed to provide equitable access of services among the populace especially the poor and to treat hospital expenditures as investments to generate additional income. As of December 2007, the province had an inventory of seven operating hospitals with an authorized bed capacity of 190 . This development was complemented by 15 Provincial Health Stations established in municipalities and in one city with no existing provincial hospital.

The Provincial Health Stations are PhilHealth-accredited facilities that serve as extension of the devolved Provincial Hospital. They provide the outpatient benefit (OPB) package and diagnostic services to the enrolled families and their dependents under the PhilHealth Sponsored Program.

Records from PEEDMO (2008) showed that the Province had invested Php 13,980,002 for Provincial Health Stations. The bulk of the investment was in 2003 when the Provincial Health Stations were constructed with a cost of Php 12,046,978. The following year (2004), the investment was Php 1,064,904. In 2006, the Province again invested in the repair of the PHS facilities amounting Php 452,200. Another investment for capital outlay in 2007 amounted to Php 415,920 for these facilities.

There are two major reasons why the province decided to establish the 15 Provincial Health Stations. First were the huge demands for consultation and outpatient benefit package services from the different rural health centers of the province, resulting to the City/Municipal Health Officers inability to visit their barangays to carry out their mandated preventive healthcare services. Second was to ensure that those sponsored families could readily access facilities offering outpatient and diagnostic services, and consultation packages under the PhilHealth Program. Number of indigents who have availed of the services provided by the Provincial Health Stations from 2002 to 2007 reached to $1,563,390$. However, it is noted that 10.33 percent or 161,505 of the facility 
beneficiaries were not sponsored members.

\section{Hospital Building Development}

The PGB has invested Php 45,120,005 from 2002 to 2007 for the upgrading of the hospital buildings. The capital outlay during this period had been highlighted by the construction of three major hospitals. The newly inaugurated Provincial Hospital in Manolo Fortich is a third level referral hospital with 45-bed capacity and a main building floor area of $1,902.50$ square meters. The total investment cost of this new hospital was Php 45,535,267 of which 91 percent or Php 41,453,000 was funded by Land Bank of the Philippines.

The Provincial Hospital in Malaybalay is being upgraded into a third level referral hospital. The hospital with its new location outside the Provincial Capitol Compound will operate with a 200-bed capacity and with its main building's floor area of 5,081 square meters. The total investment cost for the upgrading as of December 31, 2007, was Php 122,587,089. The Provincial Hospital of Maramag was also upgraded into a third level referral hospital with an authorized 100-bed capacity and with its main building's floor area of 3,362.50 square meters. The total investment cost was Php 67,900,668. Earlier in 2003, a primary 10-bed capacity hospital in Malitbog was constructed with an investment cost of Php 1,730,317.

The investments in hospital facilities aim to ease up hospital patient congestions as well as to improve hospital physical facilities. The total authorized bed capacity of the provincial hospitals is only 190, but the average hospital occupancy was 353 in 2005 to 401 in 2007. Once the upgrading of facilities is completed, the authorize bed capacity (ABC) of the provincial hospitals will increase to 410 beds from the existing authorized bed capacity of 190 beds. This will definitely ease up congestions and increase the potential income of the hospitals.

On the other hand, a detailed review of the patients admitted by the devolved hospitals from 2004 to 2007 showed that the provincial hospitals captured 37.18 percent of the total hospitalized patients in Bukidnon. Further analysis of indigent patients admitted to the different hospitals in the province showed that out of the 145,655 indigents (2004 to 2007), 50.62 percent were served by the provincial hospitals. Those indigent patients served by other hospitals in Bukidnon numbered to 71,921.

The Focus Group Dialogue with the officers and staff of the Bukidnon hospital system revealed. The following reasons why the indigent patients do not fully patronize the provincial hospitals: non-availability of drugs and medicines in the provincial hospitals and the "arrogance" of the hospital staff towards their patients.

\section{Human Resource Development}

The devolution of hospitals to the province carried with it the transfer of six hospital personnel from the Department of Health in 1992. These hospitals employed 826 personnel as of December 31, 2007. There were 400 plantilla positions, 420 on-a-job- 
order status, and six contractual posts. In terms of the medical staff breakdown, there were 129 medical doctors; 357 nurses, nursing attendants and midwives; 69 medical technologists, radiologists, and laboratory technicians among others as of December 2007.

The Provincial Indigency Health Program to which the Provincial Health Stations are attached had a personnel complement of 136. These consist of 34 technical and support staff for program management of the Provincial Indigency Health Program based at the Provincial Capitol. The different Provincial Health Stations are manned by Program Coordinators (22), Medical Doctors (15), Nurses (16), Medical Technologists (17), Midwives (16), Ambulance Drivers (14), and support personnel (2).

In terms of the financial benefits, the hospital staff enjoyed high share of the professional fees under the PhilHealth program. This is the result of the higher coverage of sponsored indigent families in Bukidnon. Records obtained from PhilHealth Provincial Office showed that for 2006 and 2007, the total professional fees paid by PhilHealth to the province amounted to Php 57,773,273 (Provincial Economic Enterprise Development and Management Office, 2008).

As employees of the provincial government, the hospital officers and personnel enjoyed the implementation of the provisions in Magna Carta for Health Workers such as laundry and subsistence allowances and hazard. They also received extra bonus, productivity incentive bonus, collective negotiated agreement and clothing allowance.

\section{Sustaining the Cost of Operation of Hospitals}

In 2004, the Sangguniang Panlalawigan of Bukidnon passed the Provincial Ordinance Number 2004-8R (9th SP). The ordinance mandates that operation of the provincial hospitals has to be treated as an economic enterprise.

As an economic enterprise, efforts were exerted to ensure that the services of the hospital are improved and reimbursements from PhilHealth are maximized. As income centers, these hospitals are semi-autonomous in their financial operation with their separate appropriation, book of account (eNGAS), bank account, and financial reports. Likewise, the hospital heads are in control of appropriation in all financial obligations (OBRE).

The province has enrolled more indigent families under the sponsored program to take advantage of the PhilHealth Capitation Fund. From 2002 to 2007, the total fund transfer (reimbursements) that the province received from PhilHealth for hospital services and the Capitation Fund reached to Php 578,019,306. However, it is disturbing to find that fund transfer from PhilHealth due to hospital services on enrolled indigent patients from 2003 to 2007 averaged only at 58 percent. The rest of the reimbursements went to other hospitals in the province.

Innovations undertaken with regard to effective fund management include the concept of bulk procurement for medicine and medical supplies. Purchases of medicine 
passing through the normal bidding process are scheduled semi-annually. The process has effectively reduced the price of the medicine procured. However, the process is met with a problem- the perennial failure of bidding. This problem is generally attributed to the non-availability of medicines in the provincial hospitals.

\section{Subsidy to Hospital Operation}

Though the hospitals generated income, the operations are being subdidized through an inter fund transfer from its General Fund. However, the amount of subsidies as against revenue generated suggests for the possibility of a complete financial independence of the hospitals.

A review of the revenue of the hospital operations as against the annual subsidy from the General Fund provides a very encouraging trend. Comparing the annual revenue generated as against the total subsidy to the hospitals from 2004 to 2007, data showed that total hospital revenue was higher than the total annual hospital subsidy.

A detailed analysis of the 2007 statement of operations of these hospitals with regard to their recurring costs showed that personnel cost the salaries and wages of permanent and casual personnel accounted for 36.29 percent. This was followed by the costs attributed to fringe and other benefits given to the personnel such as bonuses, Magna Carta for health workers, and collective negotiated agreements that accounted for 27.23 percent. Maintenance and other operating expenditures that include wages of personnel hired on-a-job-order status ranked third accounting for 22.91 percent.

\section{Potential Best Practices}

This section attempts to document potential best practices that can be drawn from the delivery of a devolved health services to the Provincial Government of Bukidnon pursuant to the devolution under the Local Government Code of 1991. The hospital reforms undertaken are be considered as potential best practices. These reforms are mainly financial. The financial reforms took steps to achieve projected hospital income levels to be used as basis for the budgetary allocation for priority capital expenditures. Schedules of hospital fees have been increased to the level of what PhilHealth allows as reimbursable as well as what the private hospital charges. However, user fees for charity/indigent patients are not instituted. The indigent patients enjoy $100 \%$ free services in provincial hospitals. This is an attempt of the province to ensure equitable access of the populace specially the poor to tertiary health services provided by the province.

\section{Partnership Agreement with PhilHealth Corporation}

The partnership of the PGB and the Philippine Health Insurance Corporation has been embodied in an agreement entered into by the Provincial Governor based on the authority given by the Sangguniang Panlalawigan with the Philippine Health Insurance Corporation. The MOA was reviewed and modified to ensure that the interests of the province are protected. The modified provisions included the use of the PhilHealth 
Liceo Journal of Higher Education Research

Capitation Fund at the discretion of the Province in terms of how it will be spent for accredited Provincial Health Stations, specific number of days with regard to transfer of the PhilHealth Capitation Fund to the province, and a specific provision with regard to number of days for the reimbursement of hospital services for sponsored indigent patients.

\section{Bukidnon Model for the PhilHealth Indigent Program}

The Bukidnon Model is essentially a scheme in the enrollment of indigent members to the PhilHealth Sponsored Program. It has the following components: (a) one effective date, (b) one sponsor, and (c) one capitation manager. The One Effective Date concept resolves the complicated implementation of the PhilHealth sponsored program that has multiple effectivity dates and multiple batches in the enrollment of sponsored families. It has not only minimized the practice of adverse selection but also leads to easier data management and efficient monitoring of indigent enrollment status.

The One Sponsor strategy enabled the PhilHealth to negotiate with one single sponsor, thus simplifying the process of renewal while minimizing operational costs. This has also minimized dual membership per household as the sponsor can employ monitoring mechanisms to avoid double membership. The One Capitation Manager scheme ensures the efficient utilization and management of the PCF while providing the sponsor with the opportunity to improve the delivery of health services.

\section{Support Mechanisms to Ensure Accessibility of the Program}

The province has adopted a policy that excess hospital charges normally shouldered by the sponsored patients under the PhilHealth Indigent Program will be shouldered by the province and not by the sponsored indigents or their beneficiaries. This move has further enhanced access to health services by providing a totally free hospital services. Also, it has forced most of the private hospitals in Bukidnon to adopt the same policy that is ultimately benefited by the vulnerable groups in the province.

Likewise, the provision for financial assistance to the different municipalities and cities of the province is adopted. This was spent for enrolled families who lack documents to support their membership such as birth certificates, marriage contracts, and registrations ensuring that the indigents are fully covered by the program of the government. This move had also improved the collection efficiency of the province as it claims for PhilHealth reimbursement.

\section{Provincial Health Stations and Hospital Facility Development}

The establishment of the Provincial Health Stations in municipalities where there is no provincial hospital has made the outpatient package services more accessible to the indigent families. The investment in hospital building facility development and medical hospital equipment has not only improved the capacities of the devolved hospitals but has also enhanced the ability of these hospitals to be income generators. These hospitals can now maximize their potential for reimbursements of services 
covered by Philippine Health Insurance Corporation.

The province's investment in hospital equipment and the adoption of "no excess payment" policy for indigent families have brought down the cost of hospital services in the province. The private hospitals have drastically reduced their laboratory fees and some have also adopted the "no excess policy" for the indigents enrolled by the province.

\section{CONCLUSIONS}

A hefty $25 \%$ to $30 \%$ of the provincial budget goes to the devolved hospital operations. Such allocation has resulted in a major rethinking by the Province on how to sustain operation and effectively pursue hospital reform initiatives. These initiatives include financial reforms, facility upgrading, and hospital category upgrading.

The national government through the province's share from the Internal Revenue Allotment is the main source of income of the province. The other major source is the PhilHealth's fund transfers to the province. Hospital services are considered potential income source and not entirely an expense source. Likewise, the enrollment of indigent families under the PhilHealth-sponsored program can also be treated as a strategy to maximize reimbursements from PhilHealth to the province.

The initiatives of the devolved hospitals are geared toward sustaining the hospital operations and ensuring that services are accessible to the poor. The initiatives include massive enrollment of the poor under the sponsored indigents program of PhilHealth, the establishment of the Provincial Health Stations that provide diagnostic consultation and outpatient package, and hospital facility development to increase the authorized bed capacity of the provincial hospitals.

The implementation of the health development plan to improve health service delivery necessitates the local government's strong political will. This requires the infusion of resources (financial, logistics, manpower, etc.), provision of mandatory benefits to the health workers, and policies that provide the legal mandates. Without political will, the realization of the intended reforms cannot be achieved.

The policy to operate the devolved hospitals as income centers is a major shift in governance with the view of sustaining hospital operations. While subsidy from the General Fund to the provincial hospitals is still substantial, the downward trend indicates attainment of financial independence over time. The financial reforms that include income retention, billing and collection system based on the financial classification of the patient demonstrate governance reforms geared towards fiscal autonomy and equity to access of services.

The Bukidnon Model provides for a win-win situation for both the PhilHealth and the Provincial Government: for PhilHealth, the opportunity to do more with less effort and resources thus enhance PhilHealth - 10 productivity; for the Provincial Government, the bulk of enrollment though a huge financial investment will eventually provide higher benefits in the form of "fee for service" reimbursement and PhilHealth 


\section{Capitation Fund.}

The Bukidnon hospital system demonstrates an attempt for cost-efficiency through an appropriate mix of primary, secondary, and tertiary hospitals to address the needs of its population. The province has upgraded its tertiary and secondary hospitals and has opened a new secondary hospital. Health reforms can be equated with the need for upgrading facilities and equipment, additional manpower to augment service delivery, and higher budget for drugs, medicines, supplies, and other maintenance and operating expenses.

\section{LITERATURE CITED}

Bossert T, \& Beauvais J (2002). Decentralization of health systems in Ghana, Zambia, Uganda and the Philippines: a comparative analysis of decision space in Health Policy and Planning; 17: 14-31. Available http://heapol.oupjournals.org/cgi/reprint/17/1/14. pdf.

Department of Health (1999). Health sector reform agenda, Philippines, 19992004.

Department of Health (2005). Fourmula one for health: the road map for health sector reforms in the Philippines 2005 - 2010 Available: www2.doh.gov.ph/F1/F1_ MAIN.htm - Cached.

Management Sciences for Health - Health sector reform technical assistance project (2001). Handbook on the capitation payment mechanism for the out-patient benefit package of PhilHealth.

Republic Act 7160 - The Local Government Code of 1991.Available: www.dilg. gov.ph/LocalGovernmentCode.aspx - 316k - Cached.

United Nations Development Programme (UNDP). (1997). Human development report: South Asia Chapter IV. Available: http://hdr.undp.org/report/detail_reports. cfm?view $=100$. 